Revista PSICOLOGIA, 2014, Vol. 28 (2), 45-62

\title{
Criatividade em contexto organizacional: o impacto de recompensas extrínsecas e do feedback negativo no desempenho criativo
}

\author{
Filipa Braia ${ }^{1}$, Luís Curral ${ }^{1}$, Catarina Gomes ${ }^{1}$ \\ ${ }^{1}$ Faculdade de Psicologia - Universidade de Lisboa
}

\begin{abstract}
Resumo: A criatividade, em contexto organizacional, tem sido definida enquanto a produção de ideias originais, úteis e apropriadas (Zhou \& Su, 2010) e constitui um passo necessário para a inovação (Amabile, 1988). No entanto, existem questões sobre as condições convenientes que estimulam a criatividade que não estão esclarecidas (Mumford, Hester \& Robledo, 2012), nomeadamente o impacto de recompensas extrínsecas (Oldham \& Baer, 2012) e o impacto do feedback negativo (Zhou, 2008). 0 presente estudo examina o efeito destes dois fatores anteriores na geração de ideias criativas. Foi realizado um estudo experimental com quatro condições ( $2 \times 2$ inter-individual), com 80 enfermeiros de um hospital central. Esta investigação contribui para obter mais conhecimento sobre as condições apropriadas para que a criatividade e a inovação prosperem nas organizações.
\end{abstract}

Palavras-chave: Criatividade; Recompensas extrínsecas; Feedback negativo; Feedback de desenvolvimento; Brainstorming individual.

Creativity in the organizational context: the impact of extrinsic rewards and negative feedback in creative performance: In the organizational context, creativity has been defined as the production of original, useful and appropriate ideas (Zhou \& Su, 2010) and it constitutes to be a necessary step for innovation (Amabile, 1988). However, some questions about the convenient conditions that stimulate creativity are not clearly answered (Mumford et al., 2012), namely the impact of extrinsic rewards (Oldham \& Baer, 2012) and the impact of negative feedback (Zhou, 2008). The present study examines the effect of extrinsic rewards and negative feedback. We conducted an experimental study with four conditions ( $2 \times 2$ between) with 80 nurses from a central hospital. This research contributes to gain more insights regarding the right conditions for creativity and innovation to flourish in organizations.

Keywords: Creativity; Extrinsic rewards; Negative feedback; Developmental feedback; Individual brainstorming.

0 paradigma mudou. Se noutros tempos, as organizações podiam responder às necessidades do mercado quase sempre com a mesma fórmula, agora têm de reinventar-se para manterem o seu valor no mercado. A competição deixou de ser limitada a um pequeno número de empresas semelhantes. Atualmente competimos contra todo o mundo. Neste contexto desafiante, a criatividade pode assumir um papel-chave para qualquer organização que deseje afirmar-se ou, até mesmo, sobreviver. As organizações devem ter a capacidade de produzir inovação e de estar recetivas a esta, e as pessoas são essenciais neste processo. São as pessoas que são criativas na resolução de problemas, na tomada de decisão, na pesquisa e no desenvolvimento de novos produtos, serviços ou métodos de trabalho (Williams \& Yang, 1999). No fundo, porque só as pessoas têm a capacidade de inventar e de sonhar. A criatividade nas organizações não constitui nenhuma capacidade transcendental. A maioria das pessoas associa a criatividade a grandes artistas, mas provavelmente não é esse tipo de criatividade o mais procurado no mundo organizacional. Às organizações, interessa a criatividade do dia a dia (Sternberg, 2012).

Pelos motivos acima referidos, a criatividade tornou-se um tópico de conversa frequente. De acordo com James e Drown (2012), no período entre 2005 e 2009 registou-se um grande aumento de investigação relativamente à criatividade nas organizações. Não obstante, apesar do aumento significativo da investigação nesta área, existem ainda questões pouco esclarecidas sobre alguns fatores subjacentes à criatividade, nomeadamente sobre os fatores que facilitam ou inibem a criatividade, e, em particular, aqueles que estão relacionados com o contexto organizacional (Mumford et al., 2012).

Esta investigação tem dois objetivos principais. Primeiro, pretende clarificar um dos tópicos mais

Dados de contacto para correspondência: Filipa Braia, Faculdade de Psicologia, Alameda da Universidade, 1649-013 Lisboa, Portugal. E-mail: filipateixeira12@hotmail.com 
controversos presentes na literatura sobre criatividade. Afinal, qual o impacto das recompensas extrínsecas na criatividade? Na comunidade científica registam-se duas opiniões (e resultados) contraditórias. Alguns autores defendem o impacto positivo das recompensas extrínsecas na criatividade (p.e., Eisenberger \& Armeli, 1997), enquanto outros defendem o oposto (p.e., Amabile, 1985). Neste sentido, alguns autores apontam para a necessidade de mais investigação sobre este tópico (Byron \& Khazanchi, 2012; Klotz, Wheeler, Halbesleben, Brock \& Bucley, 2012; Oldham \& Baer, 2012; Zou \& Shalley, 2008).

O segundo objetivo pretende responder a uma lacuna identificada por Zhou (2008) referente à transmissão de feedback negativo e o seu impacto na criatividade. Zhou (1998) identifica o feedback negativo como uma variável que pode inibir a criatividade. No entanto, na necessidade de transmitir este tipo de feedback, o que pode ser feito para amortecer o seu efeito negativo no desempenho criativo? Esta investigação pretende também contribuir para a resposta a esta pergunta.

A clarificação das questões anteriores é importante para os profissionais encarregues do desenvolvimento dos recursos humanos nas organizações. Os especialistas em recursos humanos têm, muitas vezes, capacidade para influenciar as variáveis organizacionais e contribuir para um ambiente propício à criatividade, neste caso específico através de recompensas extrínsecas e da transmissão de feedback (Waight, 2005). Embora existam vários estudos sobre criatividade, são menos aqueles que se referem ao contexto organizacional, pelo que, devido aos motivos anteriormente referidos, a mais-valia deste estudo está na sua realização em contexto real organizacional.

\section{Criatividade em Contexto Organizacional}

A criatividade organizacional diz respeito à criatividade dos colaboradores no seu contexto de trabalho e é essencial para que a inovação nas organizações aconteça. Novos produtos, abordagens ou serviços estão dependentes de ideias criativas das pessoas que constituem uma organização (Amabile, 1988). Mas o que pode ser considerado criatividade nas organizações? Atualmente, os autores definem criatividade enquanto geração de ideias originais, úteis e apropriadas (Sternberg \& Lubart, 1999; Zhou \& Su, 2010), em qualquer domínio, no que diz respeito a produtos, serviços, processos ou procedimentos, por indivíduos ou equipas (Woodman, Sawyer \& Griffin, 1993), sem que seja necessária a implementação dessas ideias (Amabile, Conti, Coon, Lazenby \& Herron, 1996).

De acordo com esta definição, as ideias são consideradas originais se forem únicas (isto é, se não existirem ideias iguais disponíveis) no contexto organizacional específico, no momento atual; úteis, se potencialmente acrescentarem valor à organização; e aplicáveis, se possíveis de serem colocadas em prática no contexto organizacional (George, 2007; Shalley, Zhou \& Oldham, 2004). A utilidade e a aplicabilidade são condições necessárias, ainda que intuitivamente a criatividade seja associada apenas à originalidade. No entanto, nas organizações de que serviria a originalidade se não pudesse ser aplicada? É necessário que as ideias também sejam úteis para responder a um problema e possíveis de serem colocadas em prática, para que efetivamente acrescentem valor ao negócio (Zhou \& Shalley, 2003).

A definição anterior foca-se, sem dúvida, no produto. Os resultados criativos podem ser qualquer produto observável, como uma ideia para uma nova abordagem ao cliente. 0 foco no produto é tipicamente utilizado nos paradigmas experimentais, nos quais a criatividade é vista como também dependente de um contexto específico (Hennessey \& Amabile, 2010). Anteriormente, os investigadores focavam-se na ideia de que a criatividade era algo feito por um tipo particular de indivíduos, uma abordagem que trouxe importantes contributos como a clarificação de traços de personalidade preditores. No entanto, no contexto organizacional, os investigadores têm vindo a assumir que todas as pessoas, com capacidades normais, podem ter um desempenho criativo, em menor ou maior grau, tendo em conta o ambiente envolvente (Amabile et al., 1996). Isto significa que, se as condições convenientes existirem, qualquer pessoa em qualquer contexto de trabalho poderá ser criativa (Shalley \& Zhou, 2008; Shalley et al., 2004). Embora existam funções que exigem mais criatividade do que outras, a criatividade não deixa de ser essencial a todas as organizações (Shalley \& Gilson, 2004; Zhou \& George, 2003).

A questão da influência do contexto está prevista num dos modelos mais referidos para estudar a criatividade, o modelo componencial de criatividade de Amabile $(1983 ; 1988)$. É um modelo importante porque faz a ligação entre fatores intra-individuais e contextuais (Pirola-Merlo \& Mann, 2004). No que se refere aos fatores intra-individuais, Amabile (1983) identifica três grandes componentes - as competências relevantes no domínio, as competências relevantes de criatividade e a motivação para a tarefa. As competências relevantes no domínio são consideradas a base para o desempenho criativo e englobam tudo o que indivíduo sabe e consegue fazer no domínio específico no qual trabalha. Relativamente às competências relevantes de criatividade, também podem ser aplicadas a qualquer domínio, e estão incluídos o estilo cognitivo favorável à tomada de novas perspetivas para os problemas; a aplicação de heurísticas para a exploração de novas vias cognitivas e o estilo de trabalho. 
Por último, a motivação para a tarefa, que nesta investigação merece especial atenção pela implicação prática que tem para as organizações. Por um lado, a motivação pode compensar um défice nas outras duas componentes, através de um esforço adicional do indivíduo para adquirir as competências (Amabile, 1988) e para manter, estimular e direcionar o comportamento (Klotz et al., 2012). Por outro lado, a motivação é uma componente fácil de influenciar através de variáveis presentes no contexto, incluindo, potencialmente, as recompensas extrínsecas e o feedback.

\section{Recompensas Extrínsecas e a Criatividade}

A criatividade não acontece no vácuo. Existem fatores presentes no contexto organizacional que inibem e favorecem a criatividade pelo efeito que têm na motivação, e um deles refere-se às recompensas extrínsecas atribuídas aos colaboradores. Pode a criatividade ser estimulada através de recompensas? Ou será que as recompensas limitam o desempenho criativo? 0 impacto das recompensas extrínsecas no desempenho criativo dos indivíduos é provavelmente o tópico mais controverso na literatura sobre criatividade, no qual os resultados empíricos e as opiniões inconsistentes não justificam a tomada de posição entre as opiniões defendidas (Byron \& Khazanchi, 2012; Hennessey \& Amabile, 2010; Oldham \& Baer, 2012).

Por exemplo, nos estudos de Eisenberger e colaboradores (Eisenberger \& Armeli, 1997; Eisenberger, Armeli \& Pretz, 1998; Eisenberger \& Aselage, 2009; Eisenberger \& Rhoades, 2001; Eisenberger \& Selbst, 1994), os resultados apontam para um efeito positivo das recompensas na criatividade. Contrariamente, nos estudos de Amabile e colaboradores (1986), de Joussemet e Koestner (1999) ou de Kruglanski, Friedman e Zeevi (1971), as recompensas apresentaram um efeito negativo na criatividade (os indivíduos com conhecimento da existência de recompensas para o desempenho da tarefa tiveram resultados menos criativos do que os indivíduos do grupo de controlo).

Estes resultados contraditórios não revelam mais do que a eterna divergência entre duas linhas de investigação, o behaviorismo e a psicologia social cognitiva. Existem muitas diferenças metodológicas nas instruções dadas, nas tarefas criativas e até mesmo na avaliação do desempenho em tais tarefas (Joussemet \& Koestner, 1999). Por exemplo, se para os investigadores behavioristas, a criatividade é igual a outro qualquer desempenho e a sua ocorrência aumenta quando reforçada, para os investigadores sociais cognitivos, as recompensas extrínsecas podem fazer com que os indivíduos se sintam controlados ou desviem a sua atenção da tarefa para a recompensa, diminuindo a motivação intrínseca (Hennessey \& Amabile, 2010).

A motivação intrínseca constitui, para os últimos, um elemento fundamental para o desempenho criativo e tem lugar de destaque no modelo de Amabile (1983). Para Amabile (1988), os indivíduos com melhor desempenho criativo são aqueles que estão motivados para a tarefa primeiramente pelo interesse, desafio e satisfação que a mesma representa e não por fatores externos. Porquê a sobreposição da motivação intrínseca? Segundo a literatura, Grant e Berry (2011) apresentam como principais mecanismos, o afeto positivo, o interesse e a curiosidade para aprender que a motivação intrínseca desperta. Sobre o afeto positivo (p.e., Amabile, Barsade, Mueller \& Staw, 2005), espera-se que aumente a gama de informações cognitivas disponíveis e a atenção para assimilar um maior conjunto de ideias; e incentive a flexibilidade cognitiva para identificar padrões e associações de ideias. Sobre o interesse e a curiosidade (p.e., Gagné \& Deci, 2005), é esperado que proporcionem uma maior predisposição para o risco, flexibilidade cognitiva e abertura à complexidade, o que poderá resultar num maior foco em novas soluções. Além disso, tanto o afeto como o interesse e a curiosidade também deverão aumentar a persistência do indivíduo perante tarefas desafiantes e complexas.

Contudo, não existe concordância nos estudos científicos para se afirmar que a motivação intrínseca é um ingrediente-chave (Grant \& Berry, 2011; Shalley et al., 2004; Zhou \& Shalley, 2003), verificando-se inconsistências nos resultados apresentados (p.e., Amabile, 1985; Amabile, Hennessey \& Grossman, 1986; Eisenberger \& Aselage, 2009; Shalley \& Perry-Smith, 2001; Zhang \& Bartol, 2010). Ainda assim, tendo em conta a importância da motivação intrínseca em outras áreas da psicologia organizacional, nesta investigação será considerada como variável de controlo.

Tal como referido anteriormente, os psicólogos sociais cognitivos defendem que as recompensas extrínsecas podem diminuir a motivação intrínseca e, consequentemente, a criatividade; pressuposto baseado na teoria da avaliação cognitiva (CET) (Ryan \& Deci, 2000). Segundo os autores, este efeito acontece porque a apresentação de recompensas extrínsecas desvia a atenção do indivíduo da tarefa para a própria recompensa; e, principalmente, pelo impacto que as recompensas extrínsecas podem ter na perceção dos indivíduos sobre a sua autonomia. De acordo com a CET (Ryan \& Deci, 2000) eventos (por exemplo, recompensas) que não promovam o sentimento de autonomia podem ser entendidos pelos indivíduos, como controladores, ao exigirem um determinado desempenho, diminuindo assim a motivação intrínseca e a criatividade (Amabile \& Pillemer, 2012; Deci, Koestner \& Ryan, 1999; Hennessey 
\& Amabile, 2010). Numa era em que a autonomia assume especial destaque nas organizações, esta teoria pode assumir-se como particularmente relevante.

Não obstante, nesta investigação é defendida a ideia de que as recompensas extrínsecas podem motivar e estimular os colaboradores para um desempenho criativo, dependendo das circunstâncias (Klotz et al., 2012). E duas razões justificam este argumento. Primeiro, as recompensas extrínsecas podem servir para reconhecer o colaborador e satisfazerem a necessidade humana de competência pessoal. Segundo, podem aumentar o envolvimento do indivíduo na atividade criativa (Shalley \& Gilson, 2004). Estes dois argumentos significam que, se o sistema de recompensas for baseado no suporte, se providenciar informação útil para o colaborador sobre o desempenho e se reconhecer a sua competência, a motivação intrínseca pode aumentar (Hennessey \& Amabile, 2010), assim como a criatividade. A informação e o reconhecimento, relativamente ao seu desempenho, podem também levar a que o indivíduo repita o comportamento no futuro (Klotz et al., 2012). Um estudo de Abbey e Dickson (1983) vai ao encontro deste raciocínio. Neste estudo, realizado com colaboradores da área de pesquisa e desenvolvimento duma empresa industrial, verificou-se que o clima de trabalho inovador englobava um sistema de recompensas que reconhecia os desempenhos excelentes. Ora, a criatividade antecede a inovação.

No entanto, as circunstâncias em que as recompensas funcionam podem variar. Por exemplo, é provável que nem todo o tipo de recompensas funcione para estimular a criatividade. Na literatura podemos identificar três tipos de recompensas utilizadas nos estudos sobre criatividade, nomeadamente as recompensas que se destinam a envolver os indivíduos (engagement-contingent reward) (p.e., Selart, Nordström, Kuvaas, Takemura, 2008), recompensas com vista a um desempenho específico (performance-contingent reward) (p.e., Selart et al., 2008) e as recompensas contingenciais à criatividade (creativity-contingent reward) (p.e., Byron \& Khazanchi, 2012).

Relativamente às recompensas que se destinam a envolver os indivíduos, este tipo de recompensas não apresenta informação nem faz qualquer exigência ou requerimento (Unsworth, Wall \& Carter, 2005) sobre o tipo de comportamento ou competência desejados, o que pode limitar o desempenho criativo (Byron \& Khazanchi, 2012). Se o indivíduo não souber que tipo de desempenho é esperado, especialmente quando é esperado mais do que um desempenho rotineiro, não é expectável que o faça corretamente. Se queremos colaboradores criativos, então é provável que tenhamos de os informar relativamente a esse aspeto. Quanto às recompensas contingentes ao desempenho, é solicitado um desempenho específico ao indivíduo, o que poderá minar a motivação intrínseca do mesmo, se este sentir a recompensa enquanto um fator de controlo (Selart et al., 2008).

Por outro lado, a solução pode estar nas recompensas contingentes à criatividade. Numa metaanálise de Byron e Khazanchi (2012) que englobou 60 estudos experimentais e não experimentais, os resultados indicaram que as recompensas contingentes à criatividade tendem a aumentar o desempenho criativo, ao contrário das recompensas focadas no desempenho rotineiro, que tendem a ter efeitos negativos na criatividade. Também Eisenberger e Shanock (2003) já haviam defendido esta ideia anteriormente. Este tipo de recompensas clarifica o comportamento desejado, ajuda a que os indivíduos entendam que tipo de competências e desempenho é esperado deles, sem propriamente controlá-los para um desempenho mais específico que envolva outros fatores como pressão ou competição. Ao envolver o critério claro de criatividade, a recompensa pode direcionar a atenção, energia e esforço dos indivíduos para o desempenho criativo (Byron \& Khazanchi, 2012; Eisenberger \& Selbst, 1994). Ao apresentar este carácter informacional e não controlador, é esperado que este tipo de recompensa estimule a criatividade, pelo que propomos a seguinte hipótese:

H1: as recompensas extrínsecas contingentes à criatividade têm um impacto positivo no desempenho criativo. Os indivíduos que recebem recompensas contingentes à criatividade têm um melhor desempenho criativo do que os indivíduos que não recebem este tipo de recompensas.

\section{Feedback Negativo e a Criatividade}

O sistema de recompensas não é o único evento contextual que pode influenciar a criatividade. Quando analisamos contextos organizacionais, percebemos que existem múltiplos fatores que podem afetar o desempenho dos indivíduos, inclusive quando o desempenho é criativo. É o caso do feedback, uma das funções chave das chefias. 0 feedback refere-se à informação recebida por um indivíduo relativamente a um comportamento que o mesmo desempenhou, providenciada por outro indivíduo que está numa posição que permite avaliar tal comportamento. Este tipo de informação permite clarificar que desempenho é esperado do indivíduo, tendo em conta objetivos estabelecidos (Ilgen, Fisher \& Taylor, 1979), pelo que o feedback é uma ferramenta útil para a modificação de comportamentos, aprendizagem e desenvolvimento (Hattie \& Timperley, 2007), além de poder também ser utilizado como estratégia motivacional, se responder a necessidades de autoestima, competência, desenvolvimento e 
autorrealização (Ilgen et al., 1979; Ryan \& Deci, 2000; Zhou, 2008).

No entanto, transmitir feedback não é um processo simples, nem acontece sempre de forma eficaz (Shalley \& Gilson, 2004), especialmente se o feedback a ser transmitido não for positivo. 0 feedback pode ter um impacto tanto positivo como negativo no indivíduo que o recebe (Hattie \& Timperley, 2007), dependendo da perceção e resposta ao mesmo, que varia de acordo com uma série de características (Ilgen et al., 1979). Particularmente no campo da criatividade, a componente informacional do feedback é muito importante porque permite que o indivíduo aprenda, compreenda e internalize padrões de trabalho considerados criativos; e facilita a aquisição de competências e estratégias criativas relevantes, que aumentam a probabilidade de os indivíduos identificarem, de forma mais exata, o problema, gerarem mais ideias e utilizarem padrões apropriados para avaliar e redefinir ideias (Zhou, 2008). 0 feedback pode, desta forma, estimular os colaboradores para um desempenho mais criativo, mas o seu impacto dependerá de fatores como o estilo e a valência da informação que é apresentada (Egan, 2005; Shalley \& Gilson, 2004; Zhou, 1998, 2008). Portanto, embora a importância do feedback não pareça ser questionável, a preocupação surge ao tentar perceber como é que esta ferramenta resulta como uma vitamina eficaz para a criatividade.

Neste sentido, Zhou (1998), num estudo no qual pretendia analisar a interação entre a valência e o estilo do feedback e a autonomia na tarefa, faz uma importante e clara distinção entre vários tipos de feedback. De acordo com a autora, o feedback pode dividir-se em termos de valência - positiva ou negativa - e em termos de estilo - informacional ou de controlo. A valência refere-se à comparação de um desempenho criativo de um indivíduo com o desempenho de outros indivíduos ou com algum outro critério identificado. Isto significa que se um indivíduo receber feedback positivo, teve um desempenho criativo melhor ou igual a um padrão ou critério. Pelo contrário, se receber feedback negativo, o indivíduo teve um desempenho criativo inferior ao estabelecido. Já o estilo, está relacionado com a forma como o feedback é transmitido. 0 estilo informacional informa sobre o desempenho, mas não coloca nenhuma restrição ou obrigação ao indivíduo. É o próprio indivíduo que mantém o controlo das suas ações e comportamentos. No estilo de controlo são impostos determinados resultados ou níveis de criatividade a atingir.

Os resultados deste estudo foram claros. Os indivíduos que receberam feedback positivo tiveram melhores resultados criativos do que os que receberam feedback negativo, assim como os indivíduos que receberam feedback informacional em detrimento dos indivíduos que receberam feedback de controlo. Ao ser analisada a interação entre o estilo e a valência, confirmou-se o esperado, o feedback positivo e informacional estimula a criatividade, ao contrário do feedback negativo e de controlo, que se assumiu como um inibidor da criatividade. Estes resultados estão consonantes com a teoria da avaliação cognitiva (Ryan \& Deci, 2000) já referida anteriormente. Ou seja, a valência positiva e o estilo informacional reconhecem a competência do indivíduo, informando-o sobre o seu desempenho, sem conter mensagens que possam ser entendidas como controladoras desse mesmo desempenho. Tal como no contexto das recompensas extrínsecas, também na literatura relacionada com o efeito do feedback na criatividade, a motivação intrínseca destaca-se. De acordo com Zhou (2008), se o feedback impulsionar ou mantiver a motivação intrínseca, é esperado que a criatividade seja estimulada. Para isso, deve reconhecer a competência e o desempenho do indivíduo, sem minar a sua autonomia (Deci et al., 1999).

O feedback negativo tende, desta forma, a desencorajar o comportamento criativo (George \& Zhou, 2001). Mesmo transmitido de forma informacional, pode ter um efeito nefasto no sentimento de competência do indivíduo e na motivação intrínseca (Guay, Vallerand \& Blanchard, 2000). Contudo, no contexto das organizações, muitas vezes é necessário transmitir feedback negativo aos colaboradores. Como deve reagir uma chefia? Ainda que a melhor solução pareça ser transmitir feedback negativo de forma informacional, a verdade é que existe uma lacuna na literatura sobre este tópico (Zhou, 2008). Esta investigação propõe que a resposta esteja no feedback de desenvolvimento.

0 feedback de desenvolvimento providencia informação que permite que os indivíduos aprendam, se desenvolvam e façam melhorias no trabalho, potenciando um desempenho mais criativo (Egan, 2005; George \& Zhou, 2007; Zhou, 2003; Zhou, \& Shalhey, 2003). Além disso, o feedback de desenvolvimento também coloca os indivíduos num modo de aprendizagem e aperfeiçoamento, no qual há maior probabilidade de os mesmos apresentarem, naturalmente, novas soluções e estratégias para problemas e melhorias relacionados com o trabalho (George \& Zhou, 2007), por direcionarem a sua energia para uma perspetiva mais construtiva sobre o seu trabalho (Egan, 2005). 0 feedback de desenvolvimento distinguese um pouco do feedback informacional. Por exemplo, no feedback informacional, o foco é apenas na questão "como estou a ir?", a informação refere-se ao desempenho ou comportamento passado, sem necessariamente abordar o futuro. Por outro lado, este último aspeto é o centro do feedback de desenvolvimento, que pretende responder à dúvida "para onde?" (Hattie \& Timperley, 2007), numa ótica de aperfeiçoamento contínuo. Permite que seja transmitida informação comportamental relevante aos 
indivíduos para que estes possam fazer melhorias no futuro (Zhou, 2003).

0 feedback de desenvolvimento está, assim, ligado aos comportamentos de suporte, por parte da chefia, que podem estimular a criatividade (Amabile, Schatzel, Moneta \& Kramer, 2004; Hennessey \& Amabile, 2010). Num estudo, George e Zhou (2007) confirmaram a importância do feedback de desenvolvimento, transmitido pelo supervisor de cada colaborador, na criatividade dos colaboradores, dependendo das circunstâncias. Também Zhou (2003) constatou que o feedback de desenvolvimento, providenciado a colaboradores na área da saúde, aumentou a probabilidade de estes colaboradores demonstrarem um desempenho mais criativo. Neste estudo foi concluído que a motivação intrínseca, dos mesmos colaboradores, aumentou através do feedback de desenvolvimento transmitido.

Tendo em conta o efeito benéfico, identificado na literatura, do feedback de desenvolvimento na criatividade, nos casos em que o indivíduo tem um desempenho criativo inferior ao esperado, será uma boa solução fornecer feedback negativo, num estilo informacional, e de seguida fornecer feedback de desenvolvimento? A presente investigação testa esta hipótese. Ainda que o feedback negativo possa implicar a diminuição da motivação intrínseca e da criatividade, provavelmente este efeito negativo pode ser diminuído se for transmitido feedback de desenvolvimento ao indivíduo imediatamente a seguir. Isto é, se forem transmitidas informações que permitam ao indivíduo aprender e desenvolver competências e estratégias importantes para a criatividade, provavelmente a criatividade é estimulada através de duas vias: o aumento do sentimento de competência e da motivação intrínseca; e a aprendizagem de novas estratégias e competências relevantes para um desempenho criativo.

Uma das estratégias que pode ser providenciada é o brainstorming. A estratégia do brainstorming é uma das técnicas mais populares para aumentar a criatividade em grupo perante um problema determinado previamente (Baruah \& Paulus, 2008), pelo que é um dos processos mais adotados, nas organizações, para a geração de ideias criativas (Heslin, 2009). Embora o brainstorming seja uma técnica clássica para a geração de ideias em grupo, também pode ser adaptado para ser utilizado a um nível individual, no qual o indivíduo é o único responsável pelo processo criativo. Alguns autores apontam para a maior eficácia e produtividade do brainstorming individual, comparativamente ao brainstorming em grupo (Smith, Linsey \& Kerne, 2010), ao nível da quantidade das ideias geradas (Harari \& Graham, 1975; Paulus \& Yang, 2000) e da originalidade de ideias (Heslin, 2009). Desta forma, a técnica do brainstorming individual, parece constituir uma ferramenta útil para a geração de ideias criativas. Tendo em conta o referencial teórico anterior, são colocadas as seguintes hipóteses:

H2a: o feedback negativo tem um impacto negativo no desempenho criativo. Após a receção do feedback negativo, os indivíduos diminuem o desempenho criativo.

H2b: o feedback de desenvolvimento (através do brainstorming individual) tem um impacto positivo no desempenho criativo. Os indivíduos que recebem feedback negativo informacional seguido de feedback de desenvolvimento têm um melhor desempenho criativo do que os indivíduos que recebem apenas feedback negativo.

\section{METODOLOGIA \\ Design e Participantes}

Foi utilizado um design experimental com quatro condições (2x2, inter-individual), no qual metade dos participantes foram informados da existência de uma recompensa pela participação em tarefas criativas e a outra metade não recebeu esta informação. Além disso, em cada uma das condições anteriores, metade dos participantes recebeu feedback negativo informacional sobre o seu desempenho e a outra metade recebeu feedback negativo informacional seguido de feedback de desenvolvimento. Os participantes foram distribuídos aleatoriamente pelas condições experimentais. Participaram 83 enfermeiros do Hospital da Horta, provenientes de todos os serviços do hospital, que correspondem a $69 \%$ da população de enfermagem do hospital. A idade média da amostra foi de 37.4 anos e $85 \%$ dos participantes eram do sexo feminino. Por último, a média de serviço dos enfermeiros naquele hospital específico era de 12.8 anos e na profissão de enfermagem de 13.91 anos.

\section{Procedimentos}

Todos os enfermeiros do hospital foram convidados, de forma voluntária, a participar no estudo. Inicialmente os participantes foram informados de que o estudo era sobre criatividade nas organizações e destinava-se a perceber a forma como as pessoas podiam ser mais criativas no seu local de trabalho. Após todas as formalidades (consentimento informado; garantia de anonimato e confidencialidade dos dados; possibilidade de desistência), procedeu-se à recolha de dados. A recolha de dados está dividida essencialmente em dois momentos. Num primeiro momento, é pedido aos participantes que respondam a um breve questionário relativamente à participação na experiência, antes de receberem qualquer instrução. Este questionário destina-se a medir a motivação intrínseca (Guay et al., 2000). De seguida são 
dadas as instruções relativamente à existência da recompensa, ao grupo que recebe recompensa; e as instruções sobre as tarefas a serem desempenhadas, a ambos os grupos.

A ambos os grupos experimentais (ao grupo "com recompensa", logo após a informação sobre a recompensa) foi explicado verbalmente que: "irá participar em duas tarefas de resolução criativa de problemas. A participação neste tipo de tarefas pressupõe que os indivíduos sejam criativos, tanto quando possível, para resolver os problemas identificados. No entanto, é necessário esclarecer que, embora associemos naturalmente a criatividade apenas ao conceito da originalidade, uma ideia realmente criativa, além de original (isto é, não existe neste contexto específico, no momento atual), é também útil, ao interveniente do problema, e possível de ser posta em prática (por exemplo, por não apresentar problemas éticos), no contexto no qual se insere. 0 objetivo é gerar o máximo número de ideias criativas que quiser e que conseguir para resolver os problemas identificados". Não foi referido qualquer padrão de desempenho específico, à exceção da referência à criatividade como um critério da tarefa proposta.

De seguida foi apresentada a primeira tarefa, com instruções escritas, que frisavam novamente a necessidade de o participante refletir sobre as três condições para uma ideia ser considerada criativa (originalidade, utilidade e aplicabilidade). Após a leitura das instruções pelo participante, o experimentador perguntou se tinha percebido o objetivo da tarefa e o problema apresentado. Depois da conclusão da primeira tarefa, os participantes responderam, novamente, ao questionário destinado a avaliar a motivação intrínseca, mas desta vez foi-lhes dito para refletirem sobre a tarefa que tinham acabado de realizar, porque o questionário destinava-se a medir o interesse na realização da tarefa anterior.

O segundo momento da experiência começa com a transmissão de feedback (falso) aos participantes sobre o seu desempenho da tarefa anterior. Ambos os grupos são divididos em duas subamostras. Uma das subamostras recebe feedback negativo informacional e a outra recebe também o feedback anterior, no entanto, recebe ainda feedback de desenvolvimento. De seguida, é entregue a segunda tarefa com um problema diferente, mas com instruções escritas iguais às apresentadas na primeira tarefa. É também dito ao participante "esta é a segunda tarefa, o objetivo é exatamente igual ao da primeira tarefa, isto é, gerar o máximo número de ideias criativas que quiser e conseguir, sem nunca esquecer que uma ideia criativa é original, útil e possível de ser posta em prática, no contexto específico". Foi igualmente perguntado aos participantes se tinham percebido o objetivo da tarefa.

Após a finalização da segunda tarefa, a motivação intrínseca foi novamente medida, através do mesmo questionário e foi dito aos participantes para terem em consideração a última tarefa realizada, ou seja, o segundo problema que lhes foi pedido para resolver. No final, foi feito um debriefing aos participantes para explicar que o feedback transmitido era falso, de acordo com um guião estabelecido, pelo que não refletia o real desempenho de cada participante. Além disso, os participantes do grupo "sem recompensa" foram informados de que também receberiam uma recompensa.

\section{Medidas}

\section{Variáveis independentes}

Recompensas extrínsecas. As recompensas extrínsecas foram manipuladas através da informação transmitida ao participante antes de ser apresentada a primeira tarefa criativa. Ao grupo que tem conhecimento da recompensa foi transmitida a seguinte informação, "antes de lhe explicar a primeira tarefa que irá desempenhar, tenho de informá-lo(a) de que, por estar a participar nestas duas tarefas de resolução criativa de problemas, irá receber uma recompensa no final da sua participação. Nós acreditamos que a criatividade é uma mais-valia nas organizações e que deve ser recompensada por isso". A instrução anterior transmite, claramente, que a recompensa é pela participação numa tarefa criativa, que é esperado que os participantes sejam criativos na resolução dos problemas apresentados, sem no entanto, estabelecer um padrão de desempenho específico, que poderia minar a criatividade. Não foi dada nenhuma informação aos participantes relativamente ao tipo de recompensa que seria entregue.

Feedback. Foi utilizado um guião específico e determinado para os dois tipos de feedback transmitidos. Este tipo de procedimento tem sido utilizado em vários estudos (p.e., Fodor \& Carver, 2000; Zhou, 1998), pelo que o feedback transmitido foi adaptado de um guião utilizado por Zhou (1998). 0 guião de feedback negativo informacional serve apenas para informar os indivíduos sobre o seu desempenho na (primeira) tarefa, tal como prevê a CET (Deci et al., 1999), pelo que foi transmitido aos participantes a seguinte informação de forma verbal, "enquanto esteve a responder ao questionário, vi atentamente as suas respostas à primeira tarefa e reparei que não foram muito criativas. Tal como lhe disse, para uma ideia ser considerada criativa, é necessário que seja original, útil e possível de ser posta em prática. Neste sentido, as suas ideias eram úteis e aplicáveis, no entanto faltou a parte da originalidade". 
Após a transmissão da informação anterior, a metade dos participantes foi entregue a segunda tarefa. A outra metade recebeu, antes da segunda tarefa, feedback de desenvolvimento através de um documento com a técnica do brainstorming descrita. Antes da entrega do documento foi transmitida a seguinte informação, "vou providenciar-lhe uma técnica que é muito utilizada para o aumento da criatividade. É muito utilizada em equipas no contexto de trabalho. Provavelmente até já a conhece, refere-se à técnica do brainstorming. Pedia-lhe que lesse as instruções e, se considerar que lhe pode ser útil para a realização da segunda tarefa, que seguisse os seus passos".

A construção do guião de brainstorming teve como base as quatro regras elaboradas por Osborn (1963), a) os indivíduos devem expressar todas as ideias de que se lembram, mesmo as ideias mais "bizarras" são permitidas, sem a preocupação imediata com a qualidade ou com a avaliação das ideias; b) não é permitido criticar ou julgar qualquer ideia; c) a ideia é gerar tantas ideias quanto possíveis; d) combinar e melhorar as ideias explicitadas para que surjam novas e melhores ideias (Baruah \& Paulus, 2008; Heslin, 2009; Linsey \& Becker, 2010). Geralmente só após uma exaustiva lista de ideias é que se procede à avaliação das mesmas. O brainstorming individual é igual ao brainstorming em grupo relativamente às regras anteriores e tipicamente inclui técnicas como a escrita livre e a associação de palavras. Tendo em conta que a participação é individual, não faria sentido optar-se pelo brainstorming em grupo.

0 documento entregue aos participantes continha a seguinte informação, "Todas as pessoas conseguem ser criativas, muitas vezes é uma questão de treino ou de aprender algumas estratégias. Quando se fala em criatividade, provavelmente associa este termo a grandes artistas, certo? Mas a criatividade não está presente apenas em obras de arte ou em grandes descobertas científicas. A criatividade também acontece no nosso dia a dia, em aspetos básicos com os quais lidamos diariamente, sem termos consciência de que estamos a ser criativos. Uma ideia criativa pode ser um novo método para organizar melhor os horários dos turnos ou a ideia de fazer um jantar mensal para aumentar o espírito de equipa. Ou então, começar a investigar um tratamento de ponta, para que os pacientes sejam melhor atendidos. Neste sentido, o brainstorming é uma ferramenta que nos ajuda a gerar ideias criativas. Geralmente é utilizado por equipas, mas também pode funcionar muito bem a um nível individual. Mais especificamente sobre esta técnica, a ideia é gerarmos o máximo de ideias que conseguirmos, sem nos importarmos se tais ideias nos parecem menos boas ou até mesmo bizarras. Não vale autocriticarmo-nos, nem sabotarmos as nossas próprias ideias. Elas poderão verificar-se brilhantes na fase da avaliação! 0 mais importante é deixar fluir as ideias na nossa cabeça com total liberdade mental. Podemos registar as nossas ideias - sejam apenas conceitos, palavras-chave ou frases - à medida que as mesmas vão surgindo, por exemplo em post-its coloridos colados na parede. Também pode ajudar se se colocar numa perspetiva diferente, por exemplo, como se fosse você o beneficiário da sua ideia criativa (o paciente, por exemplo). Só depois de gerarmos o máximo de ideias que conseguirmos é que analisamos a qualidade das ideias. Nesta fase sim devemos preocupar-nos em avaliar e selecionar as ideias que são verdadeiramente criativas, ou seja, as ideias que não estão implementadas neste momento nesta organização (originalidade) e que são úteis e podem ser postas em prática neste contexto. Temos de ter em consideração o seu benefício, para ambos os interessados, e se a ideia é eticamente possível de ser posta em prática".

\section{Variável dependente}

Criatividade. A criatividade foi medida pela avaliação das respostas dos participantes nas duas tarefas de geração de ideias. Ambas as tarefas apresentadas aos participantes eram aplicadas ao contexto de trabalho dos mesmos, de forma a estarem consonantes com a definição e o modelo de criatividade defendido, o qual prevê que as competências no domínio específico sejam relevantes e imprescindíveis para um desempenho criativo (Amabile, 1983). No entanto, as tarefas não eram demasiado específicas, isto é, não eram restritivas a uma área específica de enfermagem, mas dois problemas abrangentes e que para os quais qualquer enfermeiro deve estar contextualizado.

A primeira tarefa referia-se ao problema, "Imagine que é anunciado, no hospital no qual trabalha, que os pacientes estão internados mais tempo do que o suposto, pois o tempo de recuperação é mais lento do que o normal. Desta forma, o hospital pretende implementar medidas para reduzir o tempo de internamento dos seus pacientes. Neste sentido, pedimos-lhe que sugira ideias de medidas que possam ser implementadas com vista ao objetivo anterior". Na segunda tarefa era descrito o problema, "Imagine que é anunciado, no hospital no qual trabalha, que irão ser implementadas medidas para que os utentes tenham uma menor perceção do tempo que esperam em salas de espera (por exemplo, para consultas ou nas urgências) de forma a aumentar os índices de satisfação dos mesmos. Sugira ideias que possam ser implementadas com vista ao objetivo anterior".

Para ambas as tarefas, além das instruções verbais já referidas, foram transmitidas as seguintes 
instruções escritas, "Por favor, leia atentamente o seguinte problema e sugira ideias criativas, de forma escrita, para resolver o problema apresentado. Não se esqueça, uma ideia criativa é uma ideia original (que não está implementada nem a ser utilizada, neste momento, no seu hospital), útil, para responder ao problema identificado e apropriada (perfeitamente possível de ser posta em prática, no mesmo contexto, pois não acarreta problemas (p.e., éticos, ilegais ou económicos) nem para o hospital (incluindo a equipa hospitalar) nem para os pacientes e significa uma melhoria para os intervenientes anteriores)".

Este tipo de tarefas tem sido utilizado em vários estudos, no contexto da criatividade (p.e., Amabile et al., 1986; Joussemet \& Koestner, 1999; Selart et al., 2008; Shalley, 1991; Shalley \& Perry-Smith, 2001; Zhou, 1998). São tarefas abertas, sem uma solução óbvia ou respostas pré-determinadas, o que permite dar espaço à geração de ideias criativas.

Nesta investigação as respostas dos participantes foram avaliadas pelo diretor geral de enfermagem, que faz parte do conselho de administração do hospital atualmente, e tem 27 anos de serviço enquanto enfermeiro na organização. Cada ideia criativa dos participantes foi avaliada de acordo com uma escala de 7 pontos nos seguintes três itens referentes às três dimensões avaliadas originalidade, utilidade e aplicabilidade. Foram transmitidas as seguintes informações, "Por favor, leia atentamente todas as ideias geradas pelos participantes e classifique cada ideia, individualmente, de acordo com a seguinte escala". A escala apresentada era a seguinte:

- Originalidade (1 "nada original; 7 "extremamente original"): em que grau esta ideia é nova (i.e. não é aplicada no momento presente) no hospital para solucionar o problema apresentado?

- Aplicabilidade (1 "nada aplicável; 7 "extremamente aplicável"): em que grau esta ideia pode ser aplicada neste hospital para resolver o problema (p.e., em termos éticos, judiciais e económicos)?

- Utilidade (1 "nada útil; 7 "extremamente útil”): em que grau esta ideia é útil (para o hospital e para os pacientes) para resolver o problema apresentado?

Dado que os participantes geraram várias ideias, cada ideia foi avaliada independentemente, pelo que no final foi feita uma média de cada indivíduo para determinar o desempenho criativo geral na tarefa. 0 avaliador não teve conhecimento da identidade dos participantes nem da condição experimental à qual pertenciam, para minimizar possíveis enviesamentos nos resultados. Além disso, avaliou indivíduo por indivíduo, isto é, só após a avaliação total de um indivíduo é que o avaliador passou ao indivíduo seguinte. Procedimentos semelhantes a este têm sido utilizados noutros estudos (p.e., West \& Anderson, 1996).

\section{Variável controlo}

Motivação intrínseca. Tendo em consideração a importância que os autores atribuem à motivação intrínseca, no contexto da criatividade, esta variável foi medida apenas para efeitos de controlo, através da Escala de Motivação Situacional (SIMS) desenvolvida por Guay e colaboradores (2000). A medição da motivação intrínseca foi realizada em três momentos - antes da primeira tarefa (T1), após a primeira tarefa antes do feedback negativo (T2), e após a segunda tarefa (T3) - para verificar se os indivíduos apresentavam variabilidade após a introdução das variáveis independentes e para perceber o efeito da motivação intrínseca reportada no desempenho criativo dos mesmos.

A SIMS destina-se a medir a motivação em contexto de laboratório e em estudos de campo, no decurso de uma tarefa específica. A motivação situacional refere-se à motivação que os indivíduos experienciam aquando o envolvimento numa determinada atividade e providencia informação útil relativamente aos processos autorregulatórios dos indivíduos (Guay et al., 2000). A escala conta com 16 itens, divididos em quatro subescalas. Sobre a motivação intrínseca, os itens correspondentes são quatro: "porque penso que esta atividade é interessante", "porque considero que esta atividade é agradável", "porque esta atividade é divertida", e "porque me sinto bem quando realizo esta atividade". Cada item da escala é classificado de acordo com uma escala de Likert de 7 pontos (1 "não corresponde nada" e 7 "corresponde exatamente").

De acordo com Guay et al. (2000), a SIMS apresenta capacidade suficiente para detetar mudanças intra-individuais na motivação. Este aspeto é especialmente importante, uma vez que nesta investigação pretende-se avaliar a motivação em três momentos, dois desses momentos após a apresentação de duas variáveis independentes. Além disso, a escala não apresenta sensibilidade relativamente ao sexo do indivíduo.

Todavia, tendo em conta a origem da escala, foi utilizada uma versão portuguesa traduzida e adaptada no contexto académico português por Gamboa, Valadas e Paixão (2013). Ainda que a validação da escala tenha sido feita no contexto académico, a tradução da mesma segue completamente a escala original, não sendo registadas alterações significativas. Neste âmbito, uma vez que o propósito da escala original é a avaliação da motivação situacional em contexto laboratorial, espera-se que a adaptação desenvolvida por Gamboa et al. (2013) esteja também apta para o mesmo propósito.

Foi realizada uma análise fatorial exploratória a este instrumento, para avaliar a sua estrutura 
interna e determinar se as medidas hipotéticas medem efetivamente o que se pretende medir. A extração dos fatores foi realizada com base no método de análise em várias componentes principais com rotação oblimin. A seleção dos itens para o fator respeitou os seguintes critérios: 1) depois de ter sido realizada a rotação oblimin, consideraram-se os itens saturados a mais de $0.50 ; 2$ ) não foi eliminado nenhum dos três itens, dado que todos os itens apresentavam peso fatorial superior a 0.50 e não existiam itens ambíguos; 3) calculou-se os alfas de Cronbach, a correlação entre item e o valor global da escala, bem como o valor de alfa, caso o item fosse eliminado (Castanheira, 2005). A análise fatorial foi levada a cabo para os três tempos em que foi medida a motivação intrínseca e obteve-se um fator único, em todos os tempos, que explica 67,4\% (T1), 66,6\% (T2) e 71,8\% (T3), no qual estavam incluídos todos os itens. Alphas de .74, .74 e .80, nos momentos respetivos. Um alfa de .74 revela uma consistência aceitável e um alfa de .80 , uma boa consistência interna do instrumento. Estes resultados vão ao encontro da solução de fator único já proposta pelos autores da escala original (com um alfa de .95) e pelos autores que desenvolveram a adaptação da escala ao contexto escolar português (com um alfa de .89).

\section{Manipulation check}

Foram utilizadas duas perguntas com resposta dicotómica (sim ou não) para verificar a manipulação das variáveis independentes (feedback e recompensas extrínsecas), nomeadamente perguntou-se aos sujeitos se tinham percebido, claramente, o feedback transmitido, através da pergunta "considera que a informação transmitida, relativa ao feedback negativo, foi credível?" e "considera clara a informação transmitida relativa ao feedback negativo?"; e se tinham percebido que lhes seria atribuída uma recompensa, pela participação nas duas tarefas de resolução criativa de problemas, através da pergunta "considera clara a informação transmitida relativamente à entrega da recompensa?" e "ficou claro para si que receberia uma recompensa pela participação em duas tarefas de resolução criativa de problemas?". De acordo com os resultados da manipulation check, três indivíduos não acreditaram no feedback transmitido, pelo que a amostra final refere-se a apenas 80 enfermeiros, pela necessidade de eliminar dados referentes aos três participantes.

\section{RESULTADOS}

\section{Análises preliminares}

No Quadro 1 apresentam-se as médias e os desvios-padrão das variáveis em estudo nos diferentes tempos. De uma forma geral, ao nível da criatividade, os participantes obtiveram uma média de 4.63, na primeira tarefa e de 4.19, na segunda tarefa. Ao considerar os itens utilizados para avaliar a criatividade separadamente, o item "originalidade" apresenta uma média de 3.05 e de 4.92, na primeira e na segunda tarefa, respetivamente. No caso do item "utilidade", os resultados apresentam uma média de 5.94 na primeira tarefa e de 4.46, na segunda tarefa. Por último, o item "aplicabilidade", as médias apresentadas são 4.92 e 3.20, para as tarefas respetivamente. Quanto ao número médio de ideias geradas na primeira tarefa foi de 3.75 e de 5.34, na segunda tarefa. Sobre a motivação intrínseca, no primeiro momento, os participantes apresentaram uma média de 4.95 . Já no segundo e no terceiro momento, regista-se uma média de 5.57 e 5.75 , respetivamente.

Quadro 1. Médias e desvios-padrão das variáveis em estudo.

\begin{tabular}{lcc}
\hline & Média & DP \\
\hline Motivação intrínseca no primeiro momento (T1) & 4.95 & 0.99 \\
Avaliação da criatividade na primeira tarefa (T1) & 4.63 & 3.92 \\
Número de ideias geradas na primeira tarefa (T1) & 3.75 & 3.05 \\
Avaliação do item "originalidade" na primeira tarefa (T1) & 5.94 \\
Avaliação do item "utilidade" na primeira tarefa (T1) & 4.92 \\
Avaliação do item "aplicabilidade" na primeira tarefa (T1) & 5.57 & 1.70 \\
Motivação intrínseca no segundo momento (T2) & 4.19 & 1.52 \\
Avaliação da criatividade na segunda tarefa (T2) & 5.34 \\
Número de ideias geradas na segunda tarefa (T2) & 4.92 \\
Avaliação do item "originalidade" na segunda tarefa (T2) & 4.46 \\
Avaliação do item "utilidade" na segunda tarefa (T2) & 3.20 \\
Avaliação do item "aplicabilidade" na segunda tarefa (T2) & 5.75 \\
Motivação intrínseca no terceiro momento (T3) & 0.99 \\
\hline
\end{tabular}

A análise de variância às condições experimentais (2 (com recompensa vs. sem recompensa) x 2 (feedback negativo vs. feedback negativo e feedback de desenvolvimento)) revelou a ausência de efeito sobre o desempenho criativo na segunda tarefa $\left(F(1,79)=.204 ; p=.653 ; \eta^{2}=.003\right.$ ) (Quadro 2). Isto significa que não houve interação entre as recompensas extrínsecas e o tipo de feedback, o que permite fazer a análise individual às variáveis, no teste de hipóteses. 
Quadro 2. Médias e desvios-padrão para as condições experimentais no desempenho criativo.

\begin{tabular}{lcccc}
\hline \multirow{2}{*}{ Variável } & \multicolumn{2}{c}{ Sem recompensa } & \multicolumn{2}{c}{ Com recompensa } \\
\cline { 2 - 5 } & $\begin{array}{c}\text { Feedback } \\
\text { negativo }\end{array}$ & $\begin{array}{c}\text { Feedback negativo e de } \\
\text { desenvolvimento }\end{array}$ & $\begin{array}{c}\text { Feedback } \\
\text { negativo }\end{array}$ & $\begin{array}{c}\text { Feedback negativo e } \\
\text { de desenvolvimento }\end{array}$ \\
\hline Desempenho criativo & $4.30(.509)$ & $4.01(.513)$ & $4.17(.714)$ & $4.26(.734)$ \\
\hline
\end{tabular}

\section{Teste de hipóteses}

Para testar as nossas hipóteses foi levado a cabo um conjunto de análises de variância (ANOVA) para verificar se existiam diferenças significativas entre os indivíduos nas diferentes condições do estudo. A hipótese 1 previa que as recompensas extrínsecas contingentes à criatividade teriam um impacto positivo no desempenho criativo. Para testar esta hipótese fizemos uma ANOVA a um fator, comparando o grupo que tinha conhecimento antecipado de que iria receber uma recompensa com o grupo a quem não foi dito nada sobre uma eventual recompensa. Não se verificaram diferenças significativas quanto à introdução de recompensas $\left(F(1,78)=.491 ; p=.485\right.$; partial $\left.\eta^{2}=.006\right)$ (Quadro 3), pelo que a hipótese não foi suportada.

Quadro 3. Médias e desvios-padrão para a criatividade nas diferentes condições experimentais - "com recompensa" e "sem recompensa.

\begin{tabular}{lccc}
\hline Condição experimental & Média & Desvio-padrão & $\mathrm{N}$ \\
\hline Com recompensa & 4.70 & 0.769 & 40 \\
Sem recompensa & 4.56 & 1.047 & 40 \\
Total & 4.63 & 0.916 & 80 \\
\hline
\end{tabular}

Relativamente à hipótese 2a, esta hipótese previa que da primeira para a segunda tarefa, isto é, após a transmissão de feedback negativo, os participantes diminuiriam o desempenho criativo. Para testar esta hipótese fizemos uma ANOVA a um fator com medidas repetidas, para verificar a diferença entre o desempenho criativo dos indivíduos da primeira para a segunda tarefa. Foi verificada uma diferença significativa do tempo um (primeira tarefa) para o tempo dois (segunda tarefa) $(F(1,78)=12.40 ; p=.001$; Wilk's $\Lambda=.863$; partial $\left.\eta^{2}=.137\right)$. A média no tempo dois $\left(M_{\mathrm{t} 2}=4.19, D P=0.63\right)$ era significativamente menor do que a média no tempo um $\left(M_{\mathrm{t} 1}=4.63, D P=0.92\right)$, pelo que os resultados permitem confirmar esta hipótese (Figura 1).

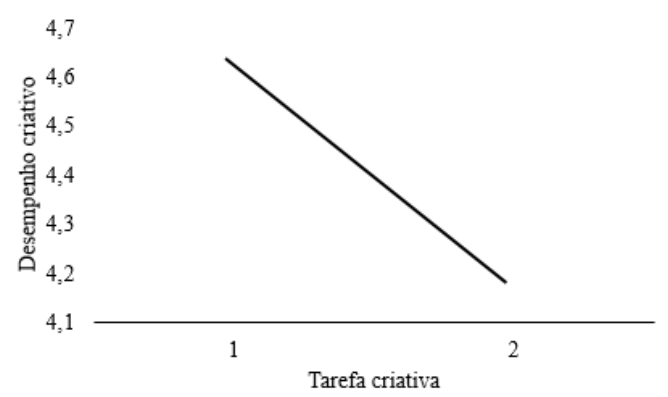

Figura 1. Diferenças no desempenho criativo dos indivíduos nas duas tarefas criativas, após a receção de feedback negativo.

Por último, a hipótese $2 \mathrm{~b}$ previa que os indivíduos que receberam feedback negativo informacional seguido de feedback de desenvolvimento teriam um melhor desempenho criativo do que os indivíduos que receberam apenas feedback negativo. Para testar esta hipótese fizemos uma ANOVA a um fator, comparando o grupo que tinha recebido apenas feedback negativo, com o grupo que tinha recebido feedback de desenvolvimento, após feedback negativo, através da técnica do brainstorming individual, na segunda tarefa. Não foi verificado um efeito do tipo de feedback transmitido $(F(1,78)=.108$; $p=.744$; Wilk's $\Lambda=.999$; partial $\left.\eta^{2}=.001\right)$. As diferenças de médias observadas entre os grupos não são estatisticamente significativas $\left(M_{\mathrm{fn}}=4.24, D P=0.615 ; M_{\mathrm{fn}+\mathrm{d}}=4.14, D P=0.638\right)$, pelo que a hipótese não foi suportada (Quadro 4).

Quadro 4. Médias e desvios-padrão para a criatividade nas diferentes condições experimentais do feedback.

\begin{tabular}{|c|c|c|c|}
\hline Condição experimental & Média & Desvio-padrão & $\mathrm{N}$ \\
\hline Feedback negativo & 4.24 & 0.62 & 40 \\
\hline Feedback negativo com feedback de desenvolvimento & 4.14 & 0.64 & 40 \\
\hline Total & 4.19 & 0.63 & 80 \\
\hline
\end{tabular}




\section{Análises suplementares}

Para um conhecimento mais aprofundado sobre as variações do desempenho criativo dos indivíduos nas duas tarefas, foram realizadas análises de medidas repetidas às três dimensões utilizadas para avaliar a criatividade, separadamente. Como referido, a análise foi realizada para verificar a existência de diferenças entre a avaliação nas duas tarefas, após a transmissão de feedback negativo; e diferenças entre os dois grupos, no que se refere ao tipo de feedback que recebem antes da segunda tarefa.

Relativamente ao item "originalidade", de acordo com a análise realizada, foram encontradas diferenças significativas entre a primeira e a segunda tarefa $(F(1,78)=57.80 ; p<.001$; Wilk's $\Lambda=.574$; partial $\left.\eta^{2}=.426\right)$. Estas diferenças indicam que os indivíduos, de ambas as condições experimentais, aumentaram a originalidade nas ideias fornecidas $\left(M_{01}=3.04, D P=1.77 ; M_{02}=4.91, D P=1.56\right)$. Também foram encontradas diferenças significativas entre os dois grupos experimentais (feedback negativo vs. feedback negativo com feedback de desenvolvimento) $\left(F(1,78)=4.73 ; p=.033\right.$; Wilk's $\Lambda=.943 ;$ partial $\eta^{2}$ $=.057$ ). A diferença encontrada nas respostas entre os indivíduos que recebem feedback negativo e os indivíduos que recebem feedback negativo seguido de feedback de desenvolvimento (brainstorming individual) indica que os participantes que recebiam apenas feedback negativo apresentaram respostas menos originais $(M=4.66, D P=1.69)$ do que os participantes que receberam feedback negativo e desenvolvimento $(M=5.17, D P=1.39)$ (Quadro 5).

No critério "utilidade", são também encontradas diferenças significativas entre a primeira e a segunda tarefa $\left(F(1,78)=47.06 ; p<.001\right.$; Wilk's $\Lambda=.624$; partial $\left.\eta^{2}=.376\right)$, que indicam que a classificação das ideias criativas dos indivíduos no item "utilidade" desce significativamente da primeira tarefa para a segunda $\left(M_{\mathrm{U} 1}=5.93, D P=1.51 ; M_{\mathrm{U} 2}=4.45, D P=1.44\right)$. Contudo, ao contrário do ocorrido no critério "originalidade", não foram verificadas diferenças entre os grupos experimentais relativamente ao tipo de feedback transmitido $\left(F(1,78)=1.34 ; p=.249\right.$; Wilk's $\Lambda=.983$; partial $\left.\eta^{2}=.017\right)$. Isto significa que tanto os indivíduos que recebem feedback negativo $(M=4.64, D P=1.40)$ como os indivíduos que recebem feedback negativo com feedback de desenvolvimento $(M=4.26, D P=1.47)$ descem as classificações no critério "utilidade" (Quadro 5). Relativamente à diferença entre o desempenho no critério "aplicabilidade" nas duas tarefas, são encontradas diferenças significativas $(F(1,78)=61.86 ; p<$ .001; Wilk's $\Lambda=.558$; partial $\eta^{2}=.442$ ), nas quais a "aplicabilidade" das ideias geradas desceu significativamente $\left(M_{\mathrm{A} 1}=4.91, D P=1.55 ; M_{\mathrm{A} 2}=3.20, D P=1.28\right)$. Mas tal como no critério "utilidade", os dados não demonstram diferenças significativas entre os grupos relativamente aos dois tipos de feedback transmitidos $\left(F(1,78)=3.48 ; p=.066\right.$; Wilk's $\Lambda=.957$; partial $\left.\eta^{2}=.043\right)$, ou seja, tanto os indivíduos que recebem feedback negativo $(M=3.40, D P=1.23)$ como os indivíduos que recebem feedback de desenvolvimento após feedback negativo $(M=2.99, D P=1.32)$ (Quadro 5).

Por último, também procedemos à análise de correlações entre as variáveis em estudo e a motivação intrínseca, para efeitos de controlo. Para as correlações entre variáveis foi utilizado o critério de Cohen e Cohen (1983) para a sua descrição. De acordo com este critério, as correlações são consideradas fracas entre 0 e .20, moderadas entre .20 e .40 e fortes acima de 40 . A motivação intrínseca no primeiro e no terceiro momentos não se correlacionou com a criatividade nem na primeira tarefa, nem com a segunda tarefa. No entanto, no que se refere à motivação no segundo momento (embora não se correlacione com a criatividade na primeira tarefa), todavia, correlaciona-se com a criatividade na segunda tarefa $(r=-.224, p=.046)$, o que significa que quanto maior é a motivação intrínseca para a tarefa (no segundo momento em que é medida), menor é o desempenho criativo do indivíduo na segunda tarefa. Além disso, os indivíduos que receberam feedback de desenvolvimento, após o feedback negativo, apresentam maiores níveis de motivação no terceiro momento, o único medido após a receção de feedback $(r=.256, p=.022)$.

Quadro 5. Médias e desvios-padrão das três dimensões utilizadas para avaliar a criatividade.

\begin{tabular}{|c|c|c|c|c|c|c|}
\hline \multirow{2}{*}{ Variável } & \multicolumn{2}{|c|}{ Feedback negativo } & \multicolumn{2}{|c|}{ Feedback negativo e de desenvolvimento } & \multicolumn{2}{|c|}{ Total } \\
\hline & 1- tarefa & $2^{\mathrm{a}}$ tarefa & 1 a tarefa & $2^{\mathrm{a}}$ tarefa & 1a tarefa & $2^{\mathrm{a}}$ tarefa \\
\hline Originalidade & $3.32(1.84)$ & $4.66(1.69)$ & $2.76(1.66)$ & $5.17(1.39)$ & $3.04(1,77)$ & $4,91(1,56)$ \\
\hline Utilidade & $5.87(1.43)$ & $4.64(1.40)$ & $5.99(1.60)$ & $4.26(1.47)$ & $5.93(1.51)$ & $4.45(1.44)$ \\
\hline Aplicabilidade & $4.71(1.49)$ & $3.40(1.23)$ & $5.11(1.59)$ & $2.99(1.32)$ & $4.91(1.55)$ & $3.20(1.28)$ \\
\hline
\end{tabular}

\section{DISCUSSÃO}

Esta investigação teve como principais objetivos estudar o efeito das recompensas extrínsecas e do feedback negativo na criatividade. Embora o impacto de recompensas extrínsecas na criatividade já tenha sido amplamente estudado, os resultados são inconsistentes e não permitem uma tomada de posição relativamente às opiniões defendidas (Klotz et al., 2012; Oldham \& Baer, 2012). Neste estudo, foi utilizado um tipo específico de recompensas identificado na literatura, as recompensas contingentes à criatividade. Ao contrário do esperado, este tipo de recompensas extrínsecas não teve impacto significativo no 
desempenho criativo dos indivíduos, o que vai contra aos resultados obtidos por Byron e Khazanchi (2012). Ainda que este tipo de recompensas providenciasse informação sobre o tipo de objetivos a serem alcançados e sobre o tipo de comportamento valorizado e esperado nas duas tarefas a desempenhar (e não minassem os sentimentos de autonomia e competência) (Byron \& Khazanchi, 2012), a recompensa não apresentou efeito na criatividade.

Uma explicação possível para a promessa de recompensas não ter tido efeito no desempenho criativo pode estar relacionada com as instruções dadas aos participantes. A ambos os grupos (com e sem recompensa) foi explicitado que o desempenho esperado era criativo ("objetivo é gerar o máximo número de ideias que quiser e que conseguir para resolver os problemas identificados"). Neste sentido, acabou por ser estabelecido um objetivo (Shalley, 1991) e um requerimento aos participantes (Unsworth et al., 2005) para um desempenho criativo. O efeito positivo do estabelecimento de objetivos para um desempenho criativo já foi previamente demonstrado por Shalley (1991) e pode servir como um mecanismo para induzir os indivíduos a desempenhar um nível desejado por meio de um efeito de priming, que leva os indivíduos a alocarem o seu esforço e atenção na criatividade. Ou seja, a promessa de recompensas pode não ter levado os indivíduos a terem um desempenho criativo superior àquele incentivado pela simples definição de objetivos criativos. Estes resultados, embora contrários aos obtidos em estudos anteriores, são consistentes com a teoria da definição de objetivos (Locke \& Latham, 2002).

No que se refere ao impacto do feedback negativo na criatividade, tal como sugerido por Zhou (1998), o feedback negativo, neste estudo, aparenta ter tido impacto negativo do desempenho criativo dos indivíduos. Ainda que a diminuição do desempenho criativo, da primeira para a segunda tarefa, não possa ser atribuída com certeza ao feedback negativo (devido à não utilização de um grupo de controlo), tendo em conta a distribuição aleatória e o controlo de variáveis, a transmissão de feedback negativo é a causa mais provável para a diminuição de desempenho identificada. No entanto, o impacto negativo do feedback negativo na criatividade não aconteceu através da diminuição da motivação intrínseca após a receção de feedback, como defendido por Zhou (1998). Nesta investigação, a motivação intrínseca dos indivíduos para a tarefa específica não se correlacionou com o desempenho criativo dos mesmos em tal tarefa específica. Após as análises suplementares aos três itens utilizados para classificar o desempenho criativo, os resultados indicaram que os indivíduos aumentaram as classificações no item "originalidade", ao contrário dos itens "utilidade" e "aplicabilidade", nos quais os indivíduos diminuíram o seu desempenho. Desta forma, a diminuição do desempenho criativo aconteceu provavelmente porque os indivíduos focaram-se no problema apresentado durante o feedback negativo - a originalidade - e esqueceram-se dos outros aspetos relevantes para que uma ideia seja considerada criativa - a utilidade e a aplicabilidade. Estes resultados suscitam uma importante reflexão sobre o impacto do feedback negativo no desempenho.

Neste estudo, o feedback negativo transmitido aparenta ter aumentado o desempenho dos participantes relativamente ao problema identificado, o que nos pode levar a pensar que a transmissão de feedback negativo informacional e específico pode ser útil para a melhoria do desempenho. Por um lado, o feedback específico permite que o indivíduo tenha conhecimento do aspeto onde teve um mau desempenho, o que torna muito mais fácil a melhoria de tal aspeto, especialmente em tarefas sem resposta óbvia (Lipnevich \& Smith, 2009). Por outro lado, o impacto positivo do feedback negativo no desempenho do indivíduo pode estar relacionado com a teoria de estabelecimento de objetivos (Locke \& Latham, 2002). Quando o feedback é negativo, os indivíduos optam por aumentar o nível de esforço quando existe um objetivo claro identificado e quando o compromisso com o mesmo é elevado, tal como a crença da probabilidade de sucesso é também elevada (Kluger \& DeNisi, 1996). Novamente, ao encontro da teoria de estabelecimento de objetivos, surge a importância do estabelecimento de requerimentos (Unsworth et al., 2005). 0 requerimento (através da ênfase na necessidade de mais originalidade nas respostas) pode ter tido influência no desempenho. Desta vez, não um requerimento para a criatividade (creative requirement) (Unsworth et al., 2005), mas um requerimento para uma das facetas da criatividade, a originalidade. Também relacionado com a teoria de estabelecimento de objetivos, Roskes, De Dreu e Nijstad (2012) sugerem que os indivíduos motivados para evitar outcomes negativos podem ser criativos quando a criatividade é percebida como funcional para o alcance de um objetivo estabelecido, o que os motiva para um esforço extra, através de um estilo de persistência cognitiva. Este argumento poderá constituir uma justificação para o impacto positivo do feedback negativo, no desempenho dos indivíduos, ao nível da originalidade.

Por último, sobre o feedback de desenvolvimento, os indivíduos que receberam este tipo de feedback através da técnica do brainstorming individual não tiveram resultados mais criativos do que os indivíduos que receberam apenas feedback negativo. Na abordagem do brainstorming os indivíduos são encorajados a gerar o máximo número de ideias, sem necessariamente pensar na sua qualidade (Paulus \& Yang, 2000). Desta forma, a avaliação das ideias em termos de utilidade e aplicabilidade pode ter faltado. 
Todavia, os indivíduos que receberam a técnica do brainstorming individual tiveram ideias ainda mais originais do que os indivíduos que receberam apenas feedback negativo. Isto sugere que o brainstorming individual pode ser uma boa técnica para gerar ideias originais. Além disso, e mais importante, o feedback de desenvolvimento aparece associado a uma maior motivação intrínseca no terceiro momento em que é medida, o que coincide com a tarefa realizada após a transmissão de feedback. Os indivíduos que receberam feedback de desenvolvimento apresentaram uma maior motivação intrínseca do que os indivíduos que receberam apenas feedback negativo. Este resultado está de acordo com um resultado obtido por Zhou (2003) e sugere que ao proporcionar aos indivíduos uma estratégia útil à melhoria do desempenho, pode fazer com que a sua motivação intrínseca aumente.

\section{LIMITAÇõES E APLICAÇõES PRÁTICAS}

Uma das limitações deste estudo refere-se à generalização dos resultados ao contexto de trabalho. É possível que os resultados obtidos apenas se verifiquem em laboratório, em tarefas relativamente curtas e num contexto no qual as variáveis são controladas. Pelo contrário, no contexto de trabalho existem outras variáveis que podem entrar em jogo e influenciar o possível impacto tanto das recompensas extrínsecas quanto do feedback no desempenho criativo. Além disso, o estudo também foi realizado com uma amostra de enfermeiros, o que não nos permite generalizar a outras populações

Uma segunda limitação está relacionada com a não utilização de grupo de controlo, no caso do feedback. Este facto não nos permite afirmar com certeza de que o desempenho diminui após a transmissão de feedback devido à transmissão do mesmo, nem que o aumento do desempenho do indivíduo no item "originalidade" acontece devido ao feedback fornecido. No entanto, tendo em conta o controlo de variáveis e a distribuição aleatória pelos grupos experimentais, a causa mais provável para ambos os acontecimentos é a transmissão de feedback negativo. Este estudo apresenta ainda uma terceira limitação referente à utilização de apenas um expert para avaliação das ideias criativas dos indivíduos. A maioria dos estudos (p.e. Shalley \& Perry-Smith, 2001; Zhou, 1998) utiliza dois ou mais experts como júris para a avaliação da criatividade. Neste estudo foi apenas possível recolher a avaliação através de um indivíduo, que, todavia, representa um cargo no conselho de administração do hospital e tem quase 30 anos de experiência na profissão e na organização.

Por último, em termos de limitações, podemos apontar também a ausência da verificação da atratividade da recompensa pelos participantes. A atratividade da recompensa pode constituir um fator condicionante para a motivação dos indivíduos e para o seu desempenho criativo. De acordo com a teoria da expectativa de Vroom (1964), o indivíduo determina a sua ação, com base nas suas perceções, atitudes e crenças, como consequência para evitar sofrimento ou aumentar o prazer. Porter e Lawler (1968) acrescentam ainda a esta teoria que o esforço individual irá depender do grau em que um outcome é valorizado pelo indivíduo. 0 valor ou atratividade da recompensa pode ter condicionado o esforço do indivíduo para a resolução da tarefa. Num estudo experimental futuro deverá ser realizada esta verificação. Aponta-se ainda a ausência de verificação da motivação do expert durante a avaliação dos participantes. Ao longo da tarefa, o expert poderá ter sofrido oscilações em termos de motivação e fadiga, o que, por sua vez, pode ter interferido com sua avaliação das ideias. Consideramos relevante que seja feita esta verificação num próximo estudo experimental.

Em termos de aplicação prática, esta investigação acrescenta uma faceta positiva ao feedback negativo. A transmissão de feedback negativo é um problema frequente nas organizações. Não são só as chefias que evitam a transmissão deste tipo de feedback, como igualmente os colaboradores muitas vezes falham em melhorar o desempenho, em resposta a este tipo de feedback (Zhou, 2008). Neste caso isso não se verificou. Os indivíduos melhoraram o desempenho no problema identificado, o que sugere que o feedback negativo, se for transmitido de forma informacional, específica e diretamente ligado à tarefa, pode ter um efeito positivo no desempenho. Ainda, segundo este estudo, o brainstorming individual apresenta-se como uma ferramenta útil à geração de ideias originais, mas não necessariamente de ideias criativas. Isto porque, provavelmente, a discussão em equipa é importante na fase de avaliação das ideias (para verificar a utilidade e aplicabilidade das mesmas). No entanto, se desejarmos que os nossos colaboradores gerem ideias com maior grau de originalidade, esta é uma boa técnica a ser treinada.

\section{ESTUDOS FUTUROS}

Em suma, tendo em conta a discussão de resultados, levantam-se algumas questões pertinentes para estudos futuros, nomeadamente ao nível da não existência de relação entre as recompensas extrínsecas e o desempenho criativo. Seria interessante perceber se o estabelecimento de um objetivo ou de um requerimento para o desempenho criativo é mais saliente, pelo menos em contexto laboratorial, do que a apresentação de recompensas extrínsecas. É também importante refletir sobre a metodologia e design mais indicados para estudar o efeito das recompensas extrínsecas na criatividade. 
Relativamente à relação positiva entre o feedback negativo e o aumento da originalidade nas ideias, além das justificações apresentadas na discussão dos resultados, outra hipótese explicativa pode residir no impacto do humor negativo na relação entre o feedback negativo e o desempenho indivíduo. De acordo com George e Zhou (2002), o humor negativo pode levar a que os indivíduos sejam mais críticos e mais exigentes a sinalizar a existência de problemas ou a necessidade de melhoria. Estes dois aspetos podem ter feito com que os indivíduos procurassem gerar respostas mais originais. Um estudo de Kaufman e Vosburg (1997) vai ao encontro deste raciocínio, no qual os indivíduos com estados de humor negativos tiveram um melhor desempenho criativo em tarefas de resolução criativa de problemas do que os indivíduos com estados de humor neutros ou positivos. Assim, pode ser interessante, em futuras investigações, estudar a relação entre o feedback negativo e o humor negativo e o impacto desta relação no desempenho criativo.

\section{Referências}

Abbey, A., \& Dickson, J. W. (1983). R\&D work climate and innovation in semicondutors. Academy of Management Journal, 26, 362-368.

Amabile, T. M. (1983). The social psychology of creativity. New York: Springer Verlag.

Amabile, T. M. (1985). Motivation and creativity: effects of motivational orientation on creative writers. Journal of Personality and Social Psychology, 48, 393-399.

Amabile, T. M. (1988). A model of creativity and innovation in organizations. In B. M. Staw, \& L. L. Cummings (Eds.), Research in Organizational Behavior (Vol. 10, pp. 123-167). Greenwich: JAI Press.

Amabile, T. M., Barsade, S. G. Mueller, J. S., \& Staw, B. M. (2005). Affect and creativity at work. Administrative Science Quarterly, 50, 367-403.

Amabile, T. M., Conti, R., Coon, H., Lazenby, J., \& Herron, M. (1996). Assessing the work environment for creativity. Academy of Management Journal, 39, 1154-1184.

Amabile, T. M., Hennessey, B. A., \& Grossman, B. S. (1986). Social influences on creativity: the effects of contracted-for reward. Journal of Personality and Social Psychology, 50, 14-23.

Amabile, T. M., \& Mueller, J. S. (2008). Studying creativity, its processes, and its antecedents: an exploration of the componential theory of creativity. In J. Zhou, \& C. E. Shalley (Eds.), Handbook of organizational creativity (pp. 33-64). New York: Lawrence Erlbaum Associates.

Amabile, T. M., \& Pillemer, J. (2012). Perspectives on the social psychology of creativity. The Journal of Creative Behavior, 46, 3-15.

Amabile, T. M., Schatzel, E. A., Moneta, G. B., \& Kramer, S. J. (2004). Leader behaviors and the work environment for creativity: perceived leader support. The Leadership Quarterly, 15, 5-32.

Baruah, J., \& Paulus, P. B. (2008). Effects of training on idea generation in groups. Small Group Research, 39, 523-541.

Byron, K., \& Khazanchi, S. (2012). Rewards and creativity performance: a meta-analytic test of theoretically derived hypotheses. Psychological Bulletin, 138, 809-830.

Castanheira, F. V. S. (2005). Exigências emocionais nos serviços pós-venda: Os fins justificam os meios? (Dissertação de mestrado não publicada). Universidade de Lisboa, Faculdade de Psicologia, Lisboa, Portugal.

Cohen, J., \& Cohen, P. (1983). Applied multiple regression/correlation analysis for the behavioral sciences ( $2^{\text {nd }}$ Ed.). Hillsdale, NJ: Erlbaum.

Deci, E. D., Koestner, R., \& Ryan, R. M. (1999). A meta-analytic review of experiments examining the effects of extrinsic rewards on intrinsic motivation. Psychological Bulletin, 125, 627-668.

Egan, T. M. (2005). Factors influencing individual creativity in workplace: an examination of quantitative empirical research. Advances in Developing Human Resources, 7, 160-181.

Eisenberger, R., \& Armeli, S. (1997). Can salient reward increase creative performance without reducing intrinsic creative interest? Journal of Personality and Social Psychology, 72, 652-663.

Eisenberger, R., Armeli, S., \& Pretz, J. (1998). Can the promise of reward increase creativity? Journal of Personality and Social Psychology, 74, 704-714.

Eiserberger, J., \& Aselage, J. (2009). Incremental effects of reward on experienced performance pressure: positive outcomes for intrinsic interest and creativity. Journal of Organizational Behavior, 30, 95117.

Eisenberger, J., \& Rhoades, L. (2001). Incremental effects of reward on creativity. Journal of Personality and Social Psychology, 81, 728-741.

Eisenberger, J., \& Shanock, L. (2003). Rewards, intrinsic motivation, and creativity: a case study of conceptual and methodological isolation. Creativity Research Journal, 15, 121-130.

Eisenberger, J., \& Selbst, M. (1994). Does reward increase or decrease creativity? Journal of Personality and Social Psychology, 66, 1116-1127. 
Fodor, E. M., \& Carver, R. A. (2000). Achievement and power motives, performance feedback, and creativity. Journal of Research in Personality, 34, 380-396.

Gagné, M., \& Deci, E. L. (2005). Self-determination theory and work motivation. Journal of Organizational Behavior, 26, 331- 362.

George, J. M. (2007). Creativity in organizations. The Academy of Management Annals, 1, 439-477.

George, J. M., \& Zhou, J. (2001). When openness to experience and conscientiousness are related to creative behavior: an interactional approach. Journal of Applied Psychology, 86, 513-524.

George, J. M., \& Zhou, J. (2002). Understanding when bad moods foster creativity and good ones don't: the role of context and clarity of feelings. Journal of Applied Psychology, 87, 687-697.

George, J. M., \& Zhou, J. (2007). Dual tuning in a supportive context: joint contributions of positive mood, negative mood, and supervisory behaviors to employee creativity. Academy of Management Journal, 50, 605-622.

Gamboa, V., Valadas, S., \& Paixão, O. (2013, Setembro). Validação da versão portuguesa da Situational Motivation Scale (SIMS) em contextos académicos. Artigo apresentado no XII Congresso Internacional Galego-Português de Psicopedagogia, Universidade do Minho, Braga, Portugal. Recuperado em: http://hdl.handle.net/10400.1/3033.

Grant, A. M., \& Berry, J. W. (2011). The necessity of others is the mother of invention: intrinsic and prosocial motivations, perspective taking and creativity. Academy of Management Journal, 54, 7396.

Guay, F., Vallerand, R. J., \& Blanchard, C. (2000). On the assessment of situational intrinsic and extrinsic motivation: the situational motivation scale (SIMS). Motivation and Emotion, 24, 175-213.

Harari, O., \& Graham, W. K. (1975). Tasks and task consequences as factors in individual and group brainstorming. The Journal of Social Psychology, 95, 61-65.

Hattie, J., \& Timperley, H. (2007). The power of feedback. Review of Educational Research, 77, 81-112.

Hennessey, B. A., \& Amabile, T. M. (2010). Creativity. Annual Review of Psychology, 61, 569-598.

Hennessey, B. A., Amabile, T. M., \& Muelle, J. S. (2011). Consensual assessment. In M. A. Runco, \& S. R. Pritzker (Eds.), Encyclopedia of creativity (2 ${ }^{\text {nd }}$ Ed., Vol. 1, pp. 253-260). San Diego: Academic Press.

Heslin, P. A. (2009). Better than brainstorming? Potential contextual boundary conditions to brainwriting for idea generation in organizations. Journal of Occupational and Organizational Psychology, 82, 129-145.

Ilgen, D. R., Fisher, C. D., \& Taylor, M. S. (1979). Consequences of individual feedback on behavior in organizations. Journal of Applied Psychology, 64, 349-371.

James, K., \& Drown, D. (2012). Organizations and creativity: trends in research, status of education and practice, agenda for the future. In M. Mumford (Ed.), Handbook of organizational creativity (pp. 1738). London, UK: Elsevier.

Joussemet, M., \& Koestner, R. (1999). Effect of expected rewards on children's creativity. Creativity Research Journal, 12, 231-239.

Kaufmann, G., \& Vosburg, S. K. (1997). "Paradoxical” mood effects on creative problem-solving. Cognition \& Emotion, 11, 151-170.

Klotz, A. C., Wheeler, A. R., Halbesleben, J. R. B., Brock, M. E., \& Buckley, M. R. (2012). Can reward systems influence the creative individual? In M. Mumford (Ed.), Handbook of organizational creativity (pp. 607-631). London, UK: Elsevier.

Kluger, A. N., \& DeNisi, A. (1996). The effects of feedback interventions on performance: a historical review, a meta-analysis and a preliminary feedback intervention theory. Psychological Bulletin, 119, 254-284.

Kruglanski, A. W., Friedman, I., \& Zeevi, G. (1971). The effects of extrinsic incentive on some qualitative aspects of task performance. Journal of Personality, 39, 606-617.

Lipnevich, A. A., \& Smith, J. K. (2009). Effects of differential feedback on students' examination performance. Journal of Experimental Psychology: Applied, 15, 319-333.

Linsey, J. S., \& Becker, B. (2010). Effectiveness of brainwriting techniques: comparing nominal groups to real teams. In T. Taura, \& Y. Nagai (Eds.), Design Creativity 2010 (pp. 165-171). London: SpringerVerlag.

Locke, E. A., \& Latham, G. P. (2002). Building a practically useful theory of goal setting and task motivation: a 35-year odyssey. The American Psychologist, 57, 705-717.

Mumford, M. D., Hester, K. S., \& Robledo, I. C. (2012). Creativity in organizations: importance and approaches. In M. Mumford (Ed.), Handbook of organizational creativity (pp. 3-16). London, UK: Elsevier.

Oldham, G. R., \& Baer, M. (2012). Creativity and the work context. In M. Mumford (Ed.), Handbook of organizational creativity (pp. 387-420). London, UK: Elsevier. 
Osborn, A. F. (1963). Applied imagination: principles and procedures of creative problem-solving (3 ${ }^{\text {rd }}$ Ed.). New York: Charles Scribner's Sons.

Paulus, P. B., \& Yang, H. C. (2000). Idea generation in groups: a basis for creativity in organizations. Organizational Behavior and Human Decision Processes, 82, 76-87.

Pirola-Merlo, A., \& Mann, L. (2004). The relationship between individual creativity and team creativity: aggregating across people and time. Journal of Organizational Behavior, 25, 235-257.

Porter, L. W., \& Lawler, E. E. (1968). Managerial attitudes and Performance. Homewood: Dorsey Press.

Roskes, M., De Dreu, C., \& Nijstad, B. A. (2012). Necessity is the mother of invention: avoidance motivation stimulates creativity through cognitive effort. Journal of Personality, 103, 242-256.

Ryan, R. M., \& Deci, E. L. (2000). Intrinsic and extrinsic motivations: classic definitions and new directions. Contemporary Educational Psychology, 25, 54-67.

Selart, M., Nordström, T., Kuvaas, B., \& Takemura, K. (2008). Effects of reward on self-regulation, intrinsic motivation and creativity. Scandinavian Journal of Educational Research, 52, 439-458.

Shalley, C. E. (1991). Effects of productivity goals, creativity goals, and personal discretion on individual creativity. Journal of Applied Psychology, 76, 179-185.

Shalley, C. E., \& Gilson, L. L. (2004). What leaders need to know: a review of social and contextual factors that can foster or hinder creativity. The Leadership Quarterly, 15, 33-53.

Shalley, C. E., \& Perry-Smith, J. E. (2001). Effects of social-psychological factors on creative performance: the role of informational and controlling expected evaluation and modeling experience. Organizational Behavior and Human Decision Processes, 84, 1-22.

Shalley, C. E., \& Zhou, J. (2008). Organizational creativity research: a historical overview. In J. Zhou, \& C. E. Shalley (Eds.), Handbook of organizational creativity (pp. 3-31). New York: Lawrence Erlbaum Associates.

Shalley, C. E., Zhou, J., \& Oldham, G. R. (2004). The effects of personal and contextual characteristics on creativity: where should we go from here? Journal of Management, 30, 933-958.

Smith, S. M., Linsey, J. S., \& Kerne, A. (2010). Using evolved analogies to overcome creative design fixation. In T. Taura, \& Y. Nagai (Eds.), Design Creativity 2010 (pp. 35-39). London: Springer-Verlag.

Sternberg, R. J. (2012). The assessment of creativity: an investment-based approach. Creativity Research Journal, 24, 3-12.

Sternberg, R. J., \& Lubart, T. I. (1999). The concept of creativity: prospects and paradigms. In R. Sternberg (Ed.), Handbook of creativity (pp. 3-15). New York: Cambridge University Press.

Unsworth, K. L., Wall, T. D., \& Carter, A. (2005). Creative Requirement: A Neglected Construct in the Study of Employee Creativity? Group Organization Management, 30, 241-260.

Vroom, V. (1964). Work and Motivation. New York: John Wiley and Sons.

Waight, C. L. (2005). Exploring connections between human resource development and creativity. Advances in Developing Human Resources, 7, 151-159.

West, M. A., \& Anderson, N. R. (1996). Innovation in top management teams. Journal of Applied Psychology, 81, 680-693.

Williams, W. M., \& Yang, L. T. (1999). Organizational creativity. In R. Sternberg (Ed.), Handbook of creativity (pp. 373- 391). New York: Cambridge University Press.

Woodman, R. W., Sawyer, J. E., \& Griffin, R. W. (1993). Toward a theory of organizational creativity. Academy of Management Review, 18, 293-321.

Zhang, X., \& Bartol, K. M. (2010). Linking empowering leadership and employee creativity: the influence of psychological empowerment, intrinsic motivation, and creativity process engagement. Academy of Management Journal, 53, 107-128.

Zhou, J. (1998). Feedback valence, feedback style, task autonomy, and achievement orientation: interactive effects on creative performance. Journal Applied Psychology, 83, 261-276.

Zhou, J. (2003). When the presence of creative coworkers is related to creativity: role of supervisor close monitoring, developmental feedback, and creative personality. Journal of Applied Psychology, 88, 413-422.

Zhou, J. (2008). Promoting creativity through feedback. In J. Zhou, \& C.E. Shalley (Eds.), Handbook of organizational creativity (pp. 125-145). New York: Lawrence Erlbaum Associates.

Zhou, J., \& George, J. (2003). Awakening employee creativity: the role of leader emotional intelligence. The Leadership Quarterly, 14, 545-568.

Zhou, J., \& Shalley, C. E. (2003). Research on employee creativity: a critical review and proposal for future research directions. In J. J. Martocchio, \& G. R. Ferris (Eds.), Research in personnel and human resource management (pp. 165-217). Oxford, England: Elsevier.

Zhou, J., \& Su, Y. (2010). A missing piece of the puzzle: the organizational context in cultural patterns of creativity. Management and Organization Review, 6, 391-413. 
Recompensas extrínsecas e feedback negativo no desempenho criativo

Historial do artigo

Recebido $\quad 31 / 07 / 2014$

Aceite $\quad 25 / 11 / 2014$

Publicado $12 / 2014$ 